\title{
The pressure method of 1-butene-3-ol epoxidation over Ti-beta catalyst
}

\author{
Agnieszka Wróblewska, Joanna Wajzberg, Eugeniusz Milchert, ${ }^{1}$ Barbara Grzmil, ${ }^{1}$ Janusz Ziebro
}

\author{
Szczecin University of Technology, Institute of Organic Chemical Technology, ul. Pulaskiego 10, 70-322 Szczecin, Poland \\ ${ }^{1}$ Szczecin University of Technology, Institute of Inorganic Chemical Technology, ul. Pułaskiego 10, 70-322 Szczecin, \\ Poland, e-mail: Agnieszka.Wroblewska@ps.pl
}

\begin{abstract}
The investigations of 1-buten-3-ol (1B3O) epoxidation by $30 \%$ hydrogen peroxide over Ti-Beta catalyst were performed. The experiments were carried out under the autogenic pressure and at the presence of methanol as a solvent. The influence of the following technological parameters on the course of epoxidation: temperature $\left(20-120^{\circ} \mathrm{C}\right)$, the molar ratio of $1 \mathrm{~B} 3 \mathrm{O} / \mathrm{H}_{2} \mathrm{O}_{2}(0.5: 1-5: 1)$, methanol concentration $(5-90 \mathrm{wt} \%$.), TiBeta concentration $(0.1-5.0 \mathrm{wt} \%)$ and the reaction time $(0.5-5.0 \mathrm{~h})$ was investigated. The main functions describing the process were: the selectivity of transformation to 1,2-epokxy-3-butanol in relation to $1 \mathrm{~B} 3 \mathrm{O}$ consumed, conversions of substrates as well as the selectivity of transformation to organic compounds in relation hydrogen peroxide consumed.
\end{abstract}

Keywords: liquid phase epoxidation, 1,2-epoxy-3-butanol, Ti-Beta catalyst.

Presented at VII Conference Wasteless Technologies and Waste Management in Chemical Industry and Agriculture, Międzyzdroje, 12 - 15 June, 2007.

\section{INTRODUCTION}

Zeolites are heterogenic catalysts used in oxidations, hydroxylation and ammoxidation processes ${ }^{1}$. Zeolite TiBeta also is one of them. The structure of this highly porous material contains, apart from oxygen, silicon and titanium atoms, little amount of aluminium atoms ${ }^{2}$. Titanium is an active centre of the catalyst and it has an ability to activate $\mathrm{H}_{2} \mathrm{O}_{2}$ in oxidation processes. The presence of aluminium gives the Ti-Beta catalyst the hydrophilic character ${ }^{2}$. The templating agent used in the synthesis of the catalyst is tetraethylammonium hydroxide (TEAOH). Ti-Beta crystallizes in the tetragonal system, and the size of its channels amounts $0.74 \mathrm{~nm}^{3}$.

Traditional methods of the epoxide synthesis rely on the intramolecular cyclization of chlorohydrins with the use of aqueous alkaline solutions or on the alkene epoxidation with per-acids. There have been developed new directions in the synthesis of this group of compounds in recent years. They rely on the elimination of organic wastes, byproducts difficult to manage and on the limitation of the quantity of the generated sewage. These objectives were archived through the catalytic processes of the oxidation of olefinic compounds with organic hydroperoxides or hydrogen peroxide. Hydrogen peroxide is considered to be the most ecological oxidizing agent in the synthesis processes.

1,2-Epoxy-3-butanol is used in the synthesis of a drug called Epothilone $\mathrm{B}^{4}$, which can act against tumour. It is also an intermediate in the synthesis of treonine ${ }^{5}$, which has an important influence on the production in a human organism: colagen, elastin and tooth enamel.

\section{EXPERIMENTAL}

There were used in the epoxidation of $1 \mathrm{~B} 3 \mathrm{O}$ the following raw materials: 1-buten-3-ol (1B3O) (97\%, Fluka), hydrogen peroxide (30\% water solution, POCh Gliwice), methanol (analytical grade, POCh Gliwice), Ti-Beta catalyst (prepared in Institute of Organic Chemical Technology, Szczecin University of Technology). Ti-Beta catalyst was synthesised by the method described by Camblor at al. ${ }^{6}$ The characterization of the catalyst was done using the following methods: XRD, XRF, IR, UV-VIS and SEM. The crystalline structure of Ti-Beta catalyst was confirmed using X-ray diffraction spectroscopy (XRD). The contents of titanium was established by the XRF method $\left(0.40 \mathrm{wt} \%\right.$ of $\left.\mathrm{TiO}_{2}\right)$. The examination was performed on the VRA 30 spectrometer. The IR spectrum of Ti-Beta catalyst was recorded on the JASCO FT/IR apparatus. There was an absorption band $960 \mathrm{~cm}^{-1}$ in the IR spectrum of the received catalyst. The UV-VIS spectrum was recorded on the SPECORD M40 apparatus. There was found in the spectrum an absorption band of $220 \mathrm{~nm}$, which confirms the presence of $\mathrm{Ti}^{4+}$ ions in the structure of the crystalline silica. The morphology of Ti-Beta crystallites was established basing on the SEM method (Figure 1) with the help of the Jeol JSM-6100 scanning microscope.

Epoxidation was performed in an autoclave under the autogenic pressure. The autoclave was fitted with a Teflon insert of the capacity of $7 \mathrm{~cm}^{3}$. The products were analyzed using a gas chromatography. The chromatographic analyses were done on the Focus apparatus equipped with the FID detector, on the Quadrex $30 \mathrm{~m}$ x $250 \mu \mathrm{m} \times 0,25 \mu \mathrm{m}$ capillary column. Hydrogen peroxide which did not react was established iodometrycally?

After the mass balance of each synthesis was done, the main functions of the process were calculated: the selectivity of the transformation to $1,2 \mathrm{E} 3 \mathrm{~B}$ in relation to $1 \mathrm{~B} 3 \mathrm{O}$ consumed, conversions of $1 \mathrm{~B} 3 \mathrm{O}$ and hydrogen peroxide as well as the selectivity of the transformation to organic compounds in relation to hydrogen peroxide consumed.

\section{RESULTS}

Epoxidation of $1 \mathrm{~B} 3 \mathrm{O}$ over the Ti-Beta catalyst using $30 \%$ hydrogen peroxide, in methanol as a solvent, leads to $1,2 \mathrm{E} 3 \mathrm{~B}$ as a main product. Depending on the conditions of the epoxidation there are formed and are established (with help of GC/MS method) different by-products in the process. The main and secondary reactions of the $1 \mathrm{~B} 3 \mathrm{O}$ epoxidation process are presented below: 


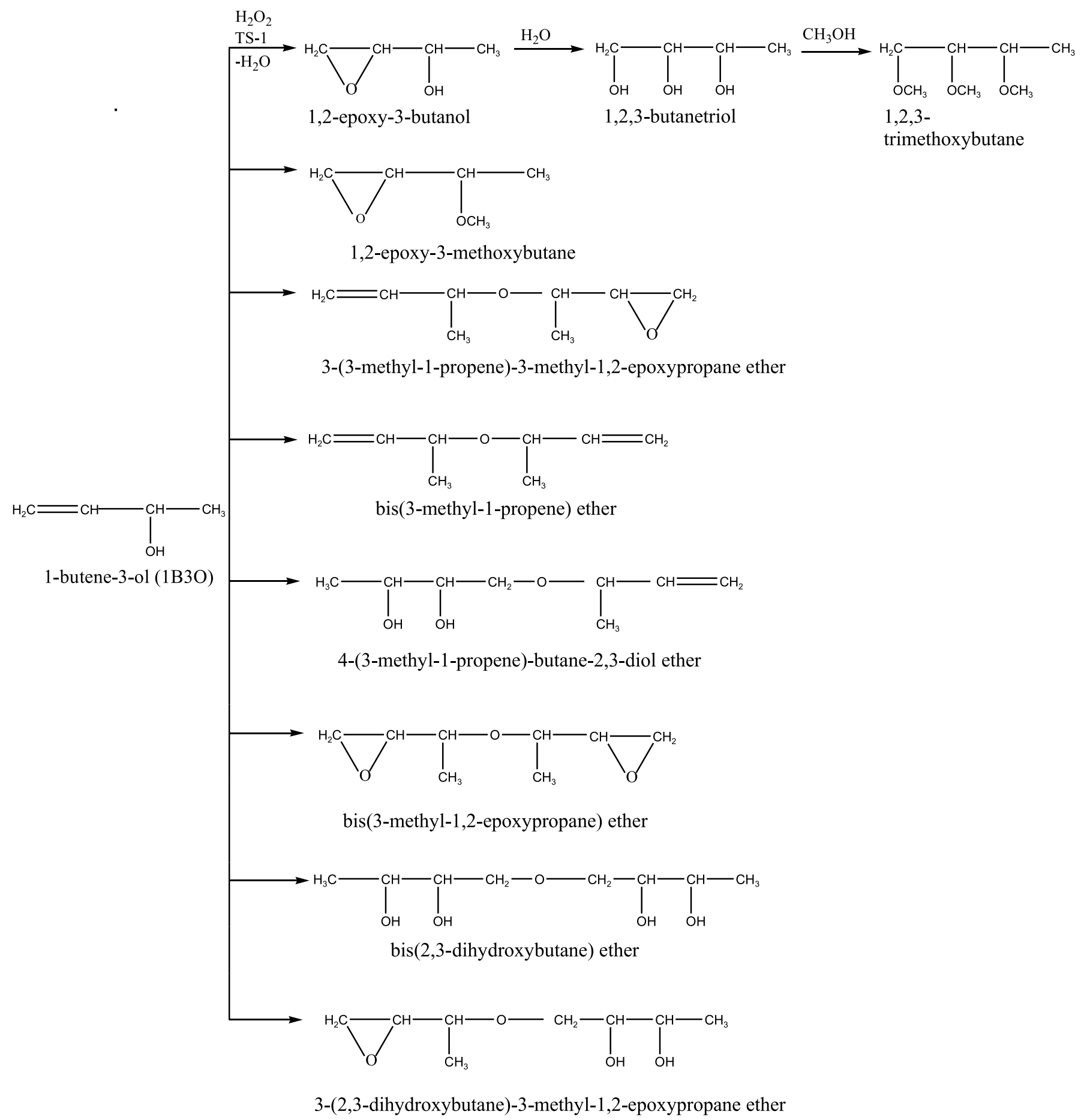

The influence of temperature on the course of $1 \mathrm{~B} 3 \mathrm{O}$ epoxidation in the autoclave was investigated in the range of $20-120^{\circ} \mathrm{C}$. The following beginning parameters were taken: the molar ratio of $1 \mathrm{~B} 3 \mathrm{O} / \mathrm{H}_{2} \mathrm{O}_{2}=1: 1$, the concentration of the solvent $40 \mathrm{wt} \%$, the concentration of $\mathrm{Ti}-$ Beta catalyst $3 \mathrm{wt} \%$ and the reaction time $3 \mathrm{~h}$. The analysis of the influence of temperature on the selectivity of the transformation to 1,2-epoxy-3-buthanol in relation to $1 \mathrm{~B} 3 \mathrm{O}$ consumed showed (Figure $2 \mathrm{a}$ ) that the increase of temperature from $20-120^{\circ} \mathrm{C}$ causes the decrease in the values of the function from $73 \mathrm{~mol} \%$ to $25 \mathrm{~mol} \%$. It is caused by forming a higher amount of 1,2,3-butanotriol. At the temperatures of 100 and $120 \mathrm{oC}$ there was also established bis(3-methyl-1-propene)ether. The other products were formed in trace amount. The conversion of $1 \mathrm{~B} 3 \mathrm{O}$ is practically constant in the tested range of temperature and equals about $75 \mathrm{~mol} \%$. The selectivity of the transformation to organic compounds in relation to $\mathrm{H}_{2} \mathrm{O}_{2}$ consumed decreases from $77 \mathrm{~mol} \%$ (for temperatures 20 $\left.-60^{\circ} \mathrm{C}\right)$ to $70 \mathrm{~mol} \%\left(100^{\circ} \mathrm{C}\right)$ and $47 \mathrm{~mol} \%\left(120^{\circ} \mathrm{C}\right)$. The conversion of $\mathrm{H}_{2} \mathrm{O}_{2}$ is constant $(96 \mathrm{~mol} \%)$. At this stage of the experiment the temperature $20^{\circ} \mathrm{C}$ was considered as optimum. However, the fact that similar values of the functions can be taken in the range of temperatures from 20 to $55^{\circ} \mathrm{C}$, must be taken into consideration.

The influence of the molar ratio of $1 \mathrm{~B} 3 \mathrm{O} / \mathrm{H}_{2} \mathrm{O}_{2}$ was investigated in the range of $0.5: 1-5: 1$ and at the temperature of $20^{\circ} \mathrm{C}$. The other beginning parameters remained without any changes. The selectivity of the transformation to $1,2 \mathrm{E} 3 \mathrm{~B}$ in relation to $1 \mathrm{~B} 3 \mathrm{O}$ consumed (Figure $2 \mathrm{~b}$ ) decreases with an increase in the molar ratio of the reagents from $73 \mathrm{~mol} \%$ to $18 \mathrm{~mol} \%$. It is caused by an excess of $1 \mathrm{~B} 3 \mathrm{O}$ comparing to $\mathrm{H}_{2} \mathrm{O}_{2}$. The conversion of $1 \mathrm{~B} 3 \mathrm{O}$ is the highest at the molar ratios of $0.5-1: 1$ and equals about $73 \mathrm{~mol} \%$. Over 1:1 there is its fall till 22 mol\% (the molar ratio of $1 \mathrm{~B} 3 \mathrm{O} / \mathrm{H}_{2} \mathrm{O}_{2}=5: 1$ ). The selec- 


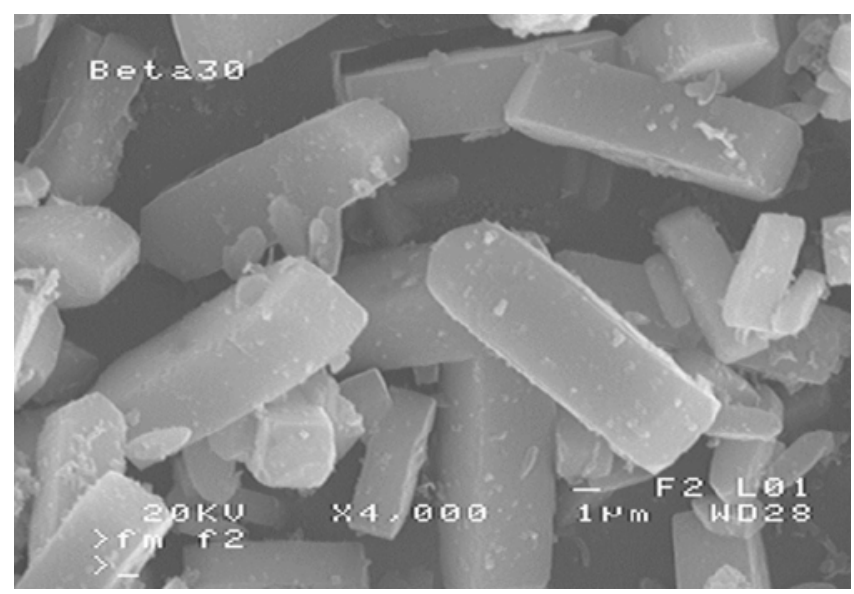

Figure 1. The SEM of the prepared Ti-Beta catalyst

tivity of the transformation to organic compounds in relation to $\mathrm{H}_{2} \mathrm{O}_{2}$ consumed increases with an increase in the molar ratio from $37 \mathrm{~mol} \%$ at molar ratio of the reagents $0.5: 1$ to $100 \mathrm{~mol} \%$ at the molar ratio of the reagents $2: 1$ and than remains constant. It means, that the whole hydrogen peroxide reacted forming organic compounds.

The influence of the methanol concentration was examined in the range of $5-90 \mathrm{wt} \%$, at the temperature of $20^{\circ} \mathrm{C}$ and at the molar ratio of $1 \mathrm{~B} 3 \mathrm{O} / \mathrm{H}_{2} \mathrm{O}_{2}=1: 1$. The other parameters were identical to the first ones. It results from Figure $2 \mathrm{c}$ that an increase in methanol concentration from 5 to $40 \mathrm{wt} \%$ causes the situation that the selectivity of the transformation of 1B3O to 1,2E3B increases from 32 to $73 \mathrm{~mol} \%$. For methanol concentrations over $40 \mathrm{wt} \%$ there appears a sudden decrease in the function value up to $0 \mathrm{~mol} \%$ at the methanol concentration of 90 wt $\%$. This phenomenon is caused by forming 1,2,3butanotriol. $1 \mathrm{~B} 3 \mathrm{O}$ conversion at concentrations from 5 to $40 \mathrm{wt} \%$ is practically constant and equals approximately $74 \mathrm{~mol} \%$. Beyond the concentration of $40 \mathrm{wt} \%$ its fall to $58 \mathrm{~mol} \%$ was observed (methanol concentration $90 \mathrm{wt} \%$ ). The selectivity of transformation to organic compounds in relation to $\mathrm{H}_{2} \mathrm{O}_{2}$ consumed changes similarly. The conversion of $\mathrm{H}_{2} \mathrm{O}_{2}$ is constant in the investigated range of methanol concentration and equals about $96 \mathrm{~mol} \%$. Methanol concentration of $40 \mathrm{wt} \%$ was considered as optimum at the stage of experiment.

The influence of the Ti-Beta catalyst concentration at the range of $0.1-5.0 \mathrm{wt} \%$ was investigated, at the temperature of $20^{\circ} \mathrm{C}$, at the molar ratio $1 \mathrm{~B} 3 \mathrm{O} / \mathrm{H}_{2} \mathrm{O}_{2}=1: 1$, methanol concentration $40 \mathrm{wt} \%$ and the reaction time $3 \mathrm{~h}$. The selectivity of the transformation to $1,2 \mathrm{E} 3 \mathrm{~B}$ in relation to $1 \mathrm{~B} 3 \mathrm{O}$ consumed (Figure 3a) increases with the rise in concentration of Ti-Beta from $30 \mathrm{~mol} \%(0.1$ wt $\%)$ to $73 \mathrm{~mol} \%$ (3.0 wt \%). At higher concentrations of Ti-Beta the value of the function slightly decreases to $67 \mathrm{~mol} \%$ ( $5 \mathrm{wt} \%$ of the catalyst). The conversion of 1B3O increases from $50 \mathrm{~mol} \%$ at the catalyst concentration 0.1 wt $\%$ to $76 \mathrm{~mol} \%$ at the catalyst concentration $3 \mathrm{wt} \%$. Rising the catalyst concentration to $5 \mathrm{wt} \%$ does not cause important changes in the value of the function. The selectivity of the transformation to organic compounds in relation to $\mathrm{H}_{2} \mathrm{O}_{2}$ consumed has a similar course. The conversion of $\mathrm{H}_{2} \mathrm{O}_{2}$ is constant at the range of the tested catalyst concentration and equals approximately $96 \mathrm{~mol} \%$. The most useful concentration of the catalyst equals 3 wt $\%$. The highest selectivity of the transformation to a)

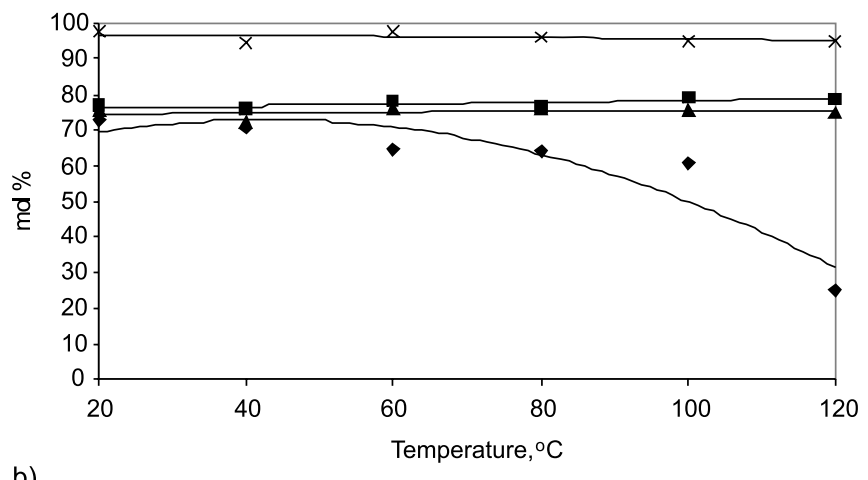

b)

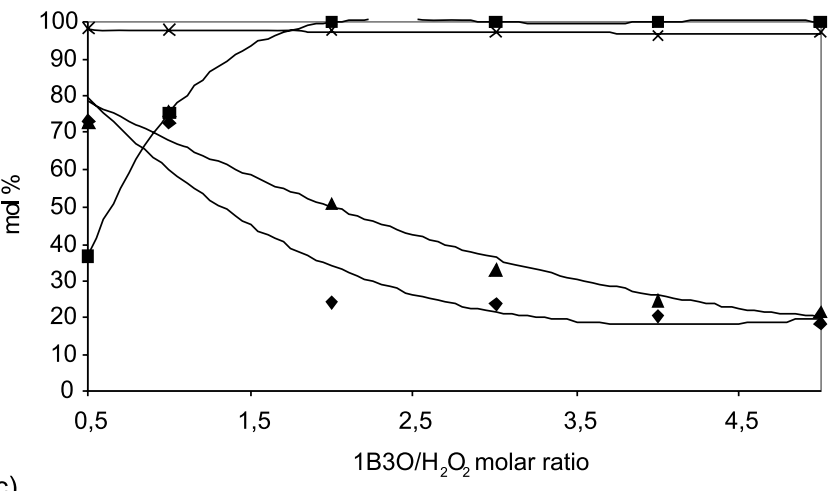

c)

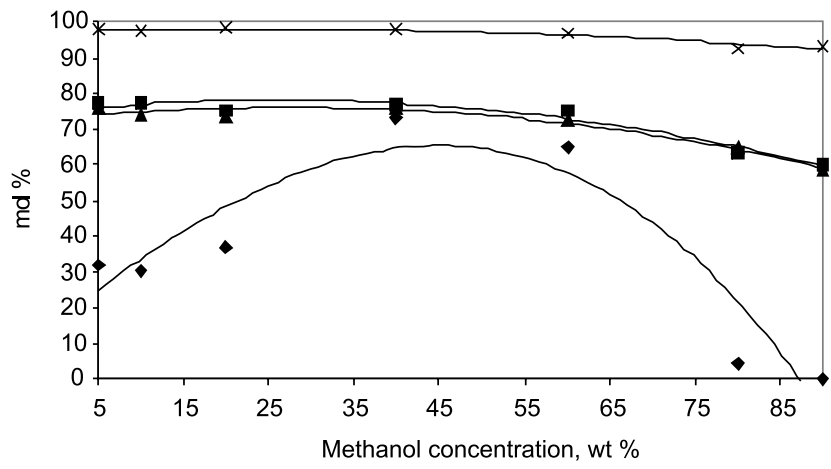

Figure 2. The effect of: a) the temperature on the selectivity of the transformation to 1,2-epoxy-3-butanol in relation to $1 \mathrm{~B} 3 \mathrm{O}$ consumed $(\diamond)$, the selectivity of the transformation to the organic compounds in relation to the consumed $\mathrm{H}_{2} \mathrm{O}_{2}(\boldsymbol{\square})$, the conversion of $1 \mathrm{~B} 3 \mathrm{O}(\boldsymbol{\Delta})$ and the conversion of $\mathrm{H}_{2} \mathrm{O}_{2}(\mathrm{x})$; b) the molar ratio $\mathrm{MAC} / \mathrm{H}_{2} \mathrm{O}_{2}$ on the selectivity of the transformation to 1,2-epoxy-3-butanol in relation to $1 \mathrm{~B} 3 \mathrm{O}$ consumed $(\diamond)$, the selectivity of the transformation to the organic compounds in relation to the consumed $\mathrm{H}_{2} \mathrm{O}_{2}(\boldsymbol{\nabla})$, the conversion of $1 \mathrm{~B} 3 \mathrm{O}(\boldsymbol{\Delta})$ and the conversion of $\mathrm{H}_{2} \mathrm{O}_{2}(\mathrm{x})$; c) methanol concentration on the selectivity of the transformation to 1,2-epoxy-3-butanol in relation to $1 \mathrm{~B} 3 \mathrm{O}$ consumed $(\checkmark)$, the selectivity of the transformation to the organic compounds in relation to the consumed $\mathrm{H}_{2} \mathrm{O}_{2}(\boldsymbol{\square})$, the conversion of $1 \mathrm{~B} 3 \mathrm{O}(\boldsymbol{\Lambda})$ and the conversion of $\mathrm{H}_{2} \mathrm{O}_{2}(\mathrm{x})$.

$1,2 \mathrm{E} 3 \mathrm{~B}$ in relation to $1 \mathrm{~B} 3 \mathrm{O}$ consumed as well as high conversion decides about it.

The influence of the reaction time was investigated in the range from $0.5 \mathrm{~h}$ to $5.0 \mathrm{~h}$. The other parameters corresponded to the values considered as the most useful at the previous stages of the experiment. From the analysis of the selectivity of the transformation to 1,2-epoxy-3butanol in relation to $1 \mathrm{~B} 3 \mathrm{O}$ consumed (Figure $3 \mathrm{~b}$ ) it 
a)

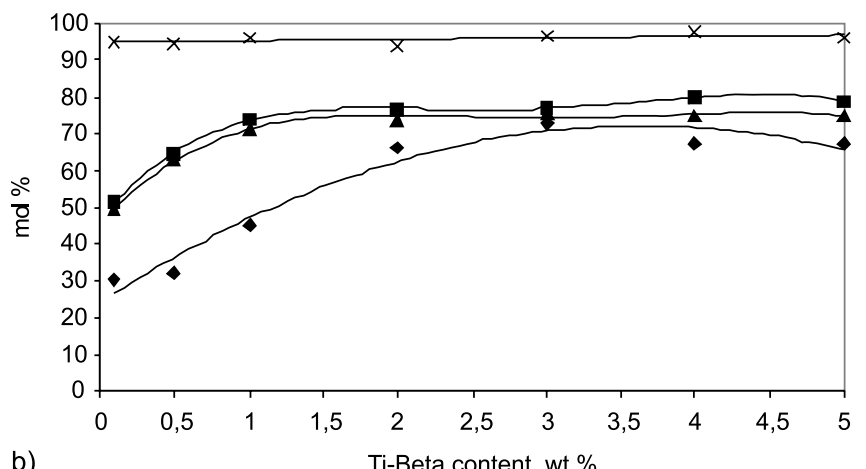

b)

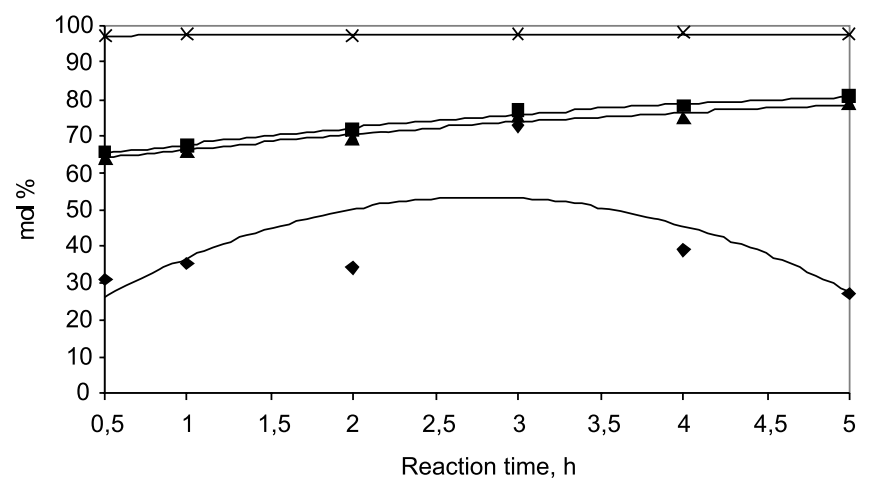

Figure 3. The effect of: a) Ti-Beta catalyst concentration on the selectivity of the transformation to 1,2-epoxy3-butanol in relation to the $1 \mathrm{~B} 3 \mathrm{O}$ consumed $(\diamond)$, the selectivity of the transformation to the organic compounds in relation to the consumed $\mathrm{H}_{2} \mathrm{O}_{2}$ $(\boldsymbol{\square})$, the conversion of $1 \mathrm{~B} 3 \mathrm{O}(\mathbf{\Delta})$ and the conversion of $\mathrm{H}_{2} \mathrm{O}_{2}(\mathrm{x})$; b) the reaction time on the selectivity of the transformation to 1,2-epoxy-3butanol in relation to the $1 \mathrm{~B} 3 \mathrm{O}$ consumed $(\diamond)$, the selectivity of the transformation to the organic compounds in relation to the consumed $\mathrm{H}_{2} \mathrm{O}_{2}$ $(\boldsymbol{\square})$, the conversion of $1 \mathrm{~B} 3 \mathrm{O}(\mathbf{\Lambda})$ and the conversion of $\mathrm{H}_{2} \mathrm{O}_{2}(\mathrm{x})$.

results that extending the time reaction from 0.5 to $3 \mathrm{~h}$ causes an increase in the value of the function from 31 mol\% to $73 \mathrm{~mol} \%$. Further lengthening of the time causes fall in its value to $27 \mathrm{~mol} \%$. Lengthening the time reaction from $0.5 \mathrm{~h}$ to $3 \mathrm{~h}$ causes rise in the conversion of 1B3O from 63 to $76 \mathrm{~mol} \%$. Further lengthening of the reaction time to $5 \mathrm{~h}$ does not have an important influence on the conversion. The selectivity of the transformation to organic compounds increases from $66 \mathrm{~mol} \%$ to $81 \mathrm{~mol} \%$ at the time range of $0.5-5.0 \mathrm{~h}$. The conversion of $\mathrm{H}_{2} \mathrm{O}_{2}$ is constant at the investigated range of reaction times and equals approximately $98 \mathrm{~mol} \%$. The analysis of the results shows that the most useful time of the reaction equals 3h.

\section{CONCLUSIONS}

The studies allowed to established the influence of technological parameters: the temperature, the molar ratio of $1 \mathrm{~B} 3 \mathrm{O} / \mathrm{H}_{2} \mathrm{O}_{2}$, methanol concentration, Ti-Beta concentration and the reaction time on the course of $1 \mathrm{~B} 3 \mathrm{O}$ epoxidation. However, the received results also depend on the nature of Ti-Beta catalyst, its ability to ineffective decomposition of hydrogen peroxide, and also a loss in the activity of the catalyst due to leaching titanium from active centres. The formed complexes of titanium do not have the same activity as the original catalyst. It results from the experiments that epoxidation of 1-buten-3-ol by $30 \%$ hydrogen peroxide at the presence of methanol as a solvent, over the Ti-Beta catalyst, performs the best at the temperature of $20^{\circ} \mathrm{C}$, at the molar ratio of $1 \mathrm{~B} 3 \mathrm{O} / \mathrm{H}_{2} \mathrm{O}_{2}$ $1: 1$, the solvent concentration $40 \mathrm{wt} \%$, the catalyst concentration $3 \mathrm{wt} \%$ and the reaction time $3 \mathrm{~h}$. Under such conditions the selectivity of the transformation to 1,2epokxy-3-butanol in relation to $1 \mathrm{~B} 3 \mathrm{O}$ consumed, equals $73 \mathrm{~mol} \%$, the conversion of $1 \mathrm{~B} 3 \mathrm{O} 76 \mathrm{~mol} \%$, the selectivity of the transformation to organic compounds in relation to $\mathrm{H}_{2} \mathrm{O}_{2}$ consumed $77 \mathrm{~mol} \%$, and the conversion of $\mathrm{H}_{2} \mathrm{O}_{2} 98 \mathrm{~mol} \%$.

\section{ACKNOWLEDDEMENT}

The research was funded by project No. R05 01901 of the State Committee for Scientific Research (KBN).

\section{LITERATURE CITED}

(1) Kelcev N.: Podstawy Techniki Adsorpcyjnej, PWN, Warszawa 1980.

(2) Van der Vaal J. C., Rigutto M. S.: Zeolite titanium beta as a selective catalyst in the epoxidation of bulky alkenes, Appl. Catal. A: General, 1980, 167, 331.

(3) Carati A., Flego C., Massara E. P., Millini R., Carluccio L., Parker W. O., Bellussi G.: Stability of Ti in MFI and Beta structures: a comparative study, Micropor. Mesopor. Mater., 1999, 30, 137.

(4) Valluri M., Hindupur R.M., Bijoy P., Labadie G., Avery M. A.: Total synthesis of Epothilone B, Org. Lett., 2001, 23, 3607.

(5) Jung M. E., Jung Y. H.: Rapid synthesis of ß-hydroxy$\beta$-amino acids, such as L-threonine, $\beta$-hydroxyphenylalanine, and B-hydroxyleucine, via an application of the Sharples asymmetric epoxidation, Tetrahed. Lett., 1989, 30, 6637.

(6) Camblor M. A., Corma A., Martinez A., Perez-Pariente J.: Synthesis of a titaniumsilicoaluminate isomorphous to zeolite beta and its application as a catalyst for the selective oxidation of large organic molecules, J. Chem. Soc., 1992, 8, 589.

(7) Brill W. F.: The Origin of Epoxides in the Liquid Phase Oxidation of Olefins with Molecular Oxygen, J. Am. Chem. Soc., 1963, 85, 141. 